Session 2793

\title{
Emphasizing Student Development in the Introduction to Engineering Sequence
}

\author{
John Williams \\ Mechanical Engineering Division \\ Alfred University \\ Alfred, NY 14802
}

\begin{abstract}
Engineering education is facing several new challenges with entering engineering freshmen. The process of education is evolving and issues are arising in terms of changing learning styles, skill levels upon entering, level of commitment to the study of engineering, and a lack of student's self understanding. Students are not aware of the demands of the engineering curriculum and most struggle in terms of how to be successful.

To address these concerns, the Introduction to Engineering sequence was modified to incorporate a significant component of "student development". Students review basic skills and learn new engineering tools while developing an understanding of the field and the demands of engineering. Focus is placed on community building, class participation and interaction, time management, study habits, problem solving, and goal setting. Initially, outcome assessment will be measured in the short term by the response of students in their end of semester course evaluations. Long term assessment will be through a comparison of grade point averages and retention rates. The statistics will be compiled for a minimum of 2 graduating classes.
\end{abstract}

\section{Introduction}

New students are unaware of the rigors of a college education. Poor study habits that were adequate in high school quickly get most students into trouble. While keeping up with the "freshman experience", they struggle with academic success. This combined with the lack of direction leads to frustration and a feeling of resentment towards the demands of the curriculum.

During deliberations by the faculty, a change in student attitude and behavior was a consistent theme. Learning styles were changing and students were less receptive to standard lecture techniques. Some students were unwilling to expend sufficient effort on their own out of class and lacked any drive to excel academically. They displayed a disturbing lack of caring about their future. Also, some students clearly entered engineering without a specific plan or goal. Most students failed to accept responsibility for their own program of study. 
Up until now, the introduction to engineering sequence was somewhat unstructured and focused on developing academic survival skills. It primarily served as a tutoring program for freshmen engineering students. This program was successful when it started ten years ago but has become less and less effective in terms of producing serious students that are prepared and committed to their study of engineering. More students were struggling with basic material at each subsequent level. Grade point averages as well as student retention rates were declining. It was decided that reform from passive support to active student development needed to begin as early in the curriculum as possible.

At Alfred University, the freshmen engineers take 4 sections of Introduction to Engineering (4 half-semester classes). The first section was heavily modified to concentrate on student development. Early support was considered to be of paramount importance to beginning students. This paper will briefly review the reasons for change and explain the methods used. Preliminary results will be evaluated through student comments and the author's observations. Changes include a more structured approach and included the adoption of the textbook Studying Engineering ${ }^{1}$. The remaining sections cover engineering tools such as CAD and computer programming. These sections were also modified to reinforce the aspect of student development. Primary changes include the addition of projects throughout the whole freshman year as well as the required participation in a campus wide competition.

\section{Methods}

The faculty met to discuss and plan a new first section of the Introduction to Engineering sequence. Specific items included course content and pedagogy to be introduced to the entering class in the fall semester of 2000. Along with a technical review of algebra, trigonometry, geometry, and physics, student development would be the main focus. Specific items to be addressed included the exploration of the engineering profession, community building, identifying and developing academic skills, and setting goals.

Many students enter engineering without much information about their intended career path. In fact, one third of the freshmen enter into engineering at Alfred University with an undecided major for the first year. These students have yet to actually understand the job for which they are training. This lack of vision prevents students from putting in a reasonable effort for satisfactory results. They are destined to fail since they are not sure where they are going. A major component of the first section is to orient all students to the different fields of engineering and the multitude of job types available. After examining the information, class discussions are used to analyze and explore individual perceptions and explore opportunities.

Community building is of paramount concern in engineering education since fellow students are

a student's greatest resource. Collaborative learning has been shown to help foster understanding and serves as a method of reinforcing classroom activities. Alfred University is primarily a liberal arts campus, which means that engineering students are mixed in with several other majors. This sometimes has the adverse effect of providing other students as poor role 
models to the engineers. Engineering students expect to succeed with the same effort put forth by those in less demanding majors. By fostering community and friendship between engineering students, social interaction would lead to a strong academic community. Students would know each other, seek out help from each other when needed, work together in study groups, and study for approximately the same amount of time. Methods included team building exercises and promoting in-class discussion of the text. Students became comfortable with each other and began to feel secure enough to participate and interact.

Most students are unaware of the academic skills required for success. They have unrealistic expectations from high school where it was easy to succeed academically. To better academic performance at the college level, academic skills and strategies are explored. First, learning styles and environmental factors were presented and discussed followed by taking a simple testing instrument for students to begin to see what style they favor. Next, study habits and time management were examined. Exercises such as scheduling and personal inventorying were performed so that students could analyze their own situation and take action using these tools.

Goal setting is one the most critical aspects to ensuring academic success. After the fields of engineering were explored and students developed individual perspectives, the rigors of an engineering education were reviewed. Getting students to define success and take personal interest generated commitment. Students exerted more effort and began to assume responsibility for the success of their education. To help ensure goals are achieved, class discussions are held to discuss values and develop reasoning skills.

To implement these strategies and be successful at improving student performance, a caring faculty must support entering students. Interaction is of paramount importance so class sizes were kept small with a student - faculty ratio of no more than 16:1. It is imperative that the instructor knows the students personally and establishes a strong relationship in a structured Introduction to Engineering sequence. This bond will allow students to work closely with the instructor to understand engineering and themselves. The main goal is to develop sufficient student motivation, planning, and effort to improve and be successful.

\section{Results}

Since this was the first semester of implementing the new Introduction to Engineering sequence, academic statistics are unavailable at the time of writing this paper. Current outcome assessment are based on comments from the anonymous Fall 2000 course evaluations and observations made by the author. Long term statistics will be tracked and reported when available.

Positive feedback was received from student responses. The most frequently observed favorable comments were regarding the introduction to the field of engineering. This orientation to engineering was the first in depth look at the profession for some students and had some profound impact on their academic career. Specific comments include; "gives some direction to which way I want to go" and "helped me to decide that I want to stick with engineering". 
Clearly, most students had blindly entered engineering with little or no guidance and no real feel for the type of career they were starting.

Another positive effect was observed in terms of community building. Students were beginning to function in groups, even beyond the classroom environment. They were starting to overcome the effects of being housed with non-engineering majors and put forth sufficient effort in their studying. This was observed in the comment "Strong points of the class include getting to know other engineers from other residence halls and getting to work together". As a community, the students were beginning to avoid separation outside of class and take advantage of each other as a resource.

The last benefit perceived by the students was the introduction and development of academic skills. Most students have had some difficulty in their academic history, but never realized the variations that exist in learning styles and the effects of environment. Interested students took advantage of the information and worked at techniques to make their specific styles work for them. Time management was another skill that students appreciated as the semester proceeded. Working on a schedule and sticking to it helped them realize how much time was necessary to succeed in engineering.

Negative comments were observed as a result of the changes as well. The most frequent comment arose from the variation of skill levels of beginning freshmen engineering students. The better-prepared students felt that nothing new was being covered. Some students resented the approach of the textbook and class to help motivate them. Comments such as "so you are telling us what, to try hard?" shows how these students felt they already knew what we were trying to develop. While finding the techniques easy to comprehend, those students that tried putting their newfound skills into action found it very challenging.

\section{Discussion}

A concentration on the aspect of student development was added to the Introduction to Engineering sequence at Alfred University. While only being implemented for the first time in the Fall of 2000, initial outcomes were assessed through student comments and observations made by the author. Future statistics based on academic performance and retention rates will provide a more robust evaluation. This paper is intended to document the initial changes to the Introduction to Engineering sequence. These modifications represent major changes to the engineering curriculum at Alfred University. Future papers will discuss the observed changes as a result of these modifications and highlight the continual development of the program.

The main goal is keeping more students in engineering while improving the necessary academic skills. From what was observed by the author, these initial changes in the curriculum will be of great benefit in the future. Students were motivated, interested, and engaged. Those who encountered difficulty during the first semester found benefit from the implementation of their newly learned skills. Those few students who found these classes uninteresting already have the 
general academic background needed to succeed but could still learn to improve skills and increase their potential. The author has observed the definite benefit derived from average students who enter engineering unsure of the profession and themselves. These students became more focused and committed to succeeding in their education.

Bibliography

1. Landis, R.B., Studying Engineering, Discovery Press, 2000.

John Williams

Dr. Williams received a Ph.D. from Clarkson University in 1998 and is currently an Assistant Professor of Mechanical Engineering at Alfred University. He enjoys teaching mechanics and materials classes in addition to performing industry sponsored research. Dr. Williams has taken an active interest in the development of the Introduction to Engineering classes at Alfred University to help freshmen gain the most from their engineering education. He is a member of ASME, MRS, and Pi Tau Sigma. 